\title{
The influence of intrauterine exposure to immunosuppressive treatment on changes in the immune system in juvenile Wistar rats
}

This article was published in the following Dove Press journal:

Drug Design, Development and Therapy

I4 July 2016

Number of times this article has been viewed

\author{
Joanna Kabat-Koperska' \\ Agnieszka Kolasa-Wołosiuk ${ }^{2}$ \\ Bartosz Wojciuk ${ }^{3}$ \\ Iwona Wojciechowska- \\ Koszko ${ }^{3}$ \\ Paulina Roszkowska ${ }^{3}$ \\ Barbara Krasnodębska- \\ Szponder ${ }^{3}$ \\ Edyta Paczkowska ${ }^{4}$ \\ Krzysztof Safranow ${ }^{5}$ \\ Edyta Gołembiewska' \\ Bogusław Machaliński ${ }^{4}$ \\ Kazimierz Ciechanowski' \\ 'Department of Nephrology, \\ Transplantology and Internal \\ Medicine, ${ }^{2}$ Department of Histology \\ and Embryology, ${ }^{3}$ Department of \\ Microbiology and Immunological \\ Diagnostics, ${ }^{4}$ Department of \\ General Pathology, ${ }^{5}$ Department of \\ Biochemistry and Medical Chemistry, \\ Pomeranian Medical University, \\ Szczecin, Poland
}

Correspondence: Joanna Kabat-Koperska Department of Nephrology,

Transplantology and Internal Medicine, Pomeranian Medical University, Al.Powst. Wlkp.72, 70-I I I Szczecin, Poland

$\mathrm{Tel}+48607650867$

Fax +48 9| 466 II 97

Email askodom@poczta.onet.pl
Background: In our study, we assessed the impact of immunosuppressive drug combinations on changes in the immune system of juvenile Wistar rats exposed to these drugs during pregnancy. We primarily concentrated on changes in two organs of the immune system - the thymus and the spleen.

Methods: The study was conducted on $40(32+8)$ female Wistar rats administered full and half dose of drugs, respectively, subjected to regimens commonly used in therapy of human kidney transplant recipients ([1] cyclosporine A, mycophenolate mofetil, and prednisone; [2] tacrolimus, mycophenolate mofetil, and prednisone; [3] cyclosporine A, everolimus, and prednisone). The animals received drugs by oral gavage 2 weeks before pregnancy and during 3 weeks of pregnancy.

Results: There were no statistically significant differences in the weight of the thymus and spleen, but changes were found in the results of blood hematology, cytometry from the spleen, and a histologic examination of the examined immune organs of juvenile Wistar rats. In the cytokine assay, changes in the level of interleukine 17 (IL-17) after increasing amounts of concanavaline A were dose-dependent; the increase of IL-17 was blocked after administration of higher doses of immunosuppressive drugs. However, after a reduction of doses, its increase resumed.

Conclusion: Qualitative, quantitative, and morphological changes in the immune system of infant rats born to pharmacologically immunosuppressed females were observed. Thymus structure, spleen composition, and splenocyte IL-17 production were mostly affected in a drug regimen-dependent manner.

Keywords: immune system, immunosuppressive drugs, kidney transplantation, pregnancy, Wistar rats

\section{Introduction}

Immunosuppressive treatment must be continued in kidney graft recipients during pregnancy. Immunosuppressive drugs and their active metabolites can cross the placental barrier and enter fetal circulation. ${ }^{1}$ Their use has been associated with an increased incidence of spontaneous abortion, prematurity, and intrauterine growth retardation..$^{2,3}$ Some immunosuppressive drugs are considered to be relatively safe during pregnancy (tacrolimus [Tc], cyclosporine A [CsA], azathioprin; and steroids), whereas others are contraindicated due to their possible toxicity (mammalian target of rapamycin [mTOR] inhibitors and mycophenolate mofetil $[\mathrm{MMF}]) .{ }^{4}$ However, experience regarding the use of many immunosuppressive drugs in human pregnancy is limited. The immune system is highly dynamic. The critical period of thymus development in rats is between 13 and 17 prenatal days. The thymus reaches its greatest relative weight at the time of 
birth. After puberty, it becomes smaller, and the portion of adipose connective tissue grows at the expense of lymphatic tissue. By the third postnatal week, the spleen is formed as a fully functional organ..$^{5}$ In our experimental study, we assessed the impact of safe and contraindicated immunosuppressants in combinations on changes in the immune system in juvenile Wistar rats after exposure during pregnancy. We mainly concentrated on morphology and function in two central organs of the immune system - the thymus and the spleen. Wistar rats were chosen as suitable subjects for immunotoxicity studies and due to their susceptibility to immunosuppressive drugs. ${ }^{6}$

\section{Materials and methods}

\section{Animals and treatment}

The study was conducted on 32 female and eight male Wistar rats (from the Centre of Experimental Medicine, Medical University in Bialystok, Poland). At the start of the experiment, the rats were 12 weeks old and their mean weight was $230 \mathrm{~g}$. The animals had genetic and health certificates issued by a veterinarian. This study was approved by the Local Ethical Committee for Experiments on Animals in Szczecin (No 12/2013, dated October 24, 2013), and the experiments were in compliance with animal care guidelines issued by the committee. The animals were housed singly, kept on a 12-hour light-dark cycle, and were given feed Labofeed $\mathrm{H}$ (Morawski, Kcynia, Poland) and water ad libitum.

The experiments were performed using the pharmaceutical form of each drug. The animals received drugs by oral gavage. The doses used in the study were as follows: Tc (Prograf; Astellas, Northbrook, IL, USA): 4 mg/kg/d; MMF (CellCept; Hoffmannn-La Roche Ltd., Basel, Switzerland): 20 mg/kg/d; CsA (Sandimmun Neoral; Novartis, Basel, Switzerland): $5 \mathrm{mg} / \mathrm{kg} / \mathrm{d}$; everolimus (Certican; Novartis): $0.5 \mathrm{mg} / \mathrm{kg} / \mathrm{d}$; and prednisone (Encorton; Polfa, Warsaw, Poland): $4 \mathrm{mg} / \mathrm{kg} / \mathrm{d}$. The drug doses were based on data available in literature. ${ }^{7-15}$ The female rats $(n=32)$ were divided into four groups:

- Control group $(n=8)$ - no drugs, but rats were given the gavage base and olive oil under otherwise identical conditions to the other rats used in the experiment;

- CMG group $(n=8)$ - received CsA, MMF, and prednisone;

- TMG group $(\mathrm{n}=8)$ - received Tc, MMF, and prednisone;

- CEG group $(\mathrm{n}=8)$ - received CsA, everolimus, and prednisone.

The animals received medication every 24 hours for approximately 5 weeks ( 2 weeks after the acclimatization period prior to mating - when placed with males $1: 1$ in separate cages - and later after mating during 3 weeks of pregnancy). After mating, each pregnant female rat was housed in a separate cage. Once a week, the animals were weighed again, and medication dose was adequately adjusted based on the changed weight. After delivery, the treatment was stopped (no drugs were administered during lactation period). Thirty-one female rats completed the study.

Eighty-three pups from nine litters were born -69 pups from the control group (six litters), 13 pups from the $\mathrm{CMG}$ group (two litters; one pup died at the age of 3 days), and only one pup from the CEG group. No pups from the TMG group were born. Six 19-day-old rats from the CMG group were euthanized as they seemed unable to reach the age of 8 weeks because of visible abnormalities (hydrocephaly, anophthalmia, and apathy). They were euthanized together with six rats from the control group at the age of the corresponding day. The rest of the juvenile rats from the $\mathrm{CMG}$ group (five, one more died later at age of 28 days) were sacrificed 8 weeks after their birth (with corresponding group of 12 rats born to control mothers).

As only a small number of rats were born to mothers in the treatment groups, the experiment was repeated with half the dose of study drugs (although the dose of steroid remained the same). We used an additional group of eight 12-week-old female rats divided in three separate groups (two rats received the same drug combination as the CMG groupknown as CMG group 0.5; three rats were given the same drug combination as the TMG group - called TMG group 0.5 ; and three rats had the same drug combination as the CEG group - called CEG group 0.5). The study included as few animals as possible owing to ethical reasons, and we expected more pups per litter from each dam (at least 12-20 pups for each treatment group for analysis). This additional study was approved by the Local Ethical Committee for Experiments on Animals in Szczecin (No 10/2014 and No 11/2014, both dated June 6, 2014). The experiments were in compliance with animal care guidelines issued by the committee. The doses used in the study were as follows: Tc: $2 \mathrm{mg} / \mathrm{kg} / \mathrm{d}$; MMF: $10 \mathrm{mg} / \mathrm{kg} / \mathrm{d}$; CsA: $2.5 \mathrm{mg} / \mathrm{kg} / \mathrm{d}$; everolimus: $0.25 \mathrm{mg} / \mathrm{kg} / \mathrm{d}$; and prednisone: $4 \mathrm{mg} / \mathrm{kg} / \mathrm{d}$. The rest of the procedures were identical as the first part of the experiment.

All eight female rats completed the second part of the study. A total of 63 pups from seven litters were born 24 pups from CMG group 0.5 (two litters), 32 pups from TMG group 0.5 (three litters), and seven pups from CEG group 0.5 (two litters). One female rat from CEG group 0.5 delivered no pups. The juvenile rats from these groups were 
sacrificed 8 weeks after birth (12 rats from CMG group 0.5, 12 rats from TMG group 0.5 , and all seven rats from CEG group 0.5).

All juvenile rats were euthanized by pentobarbital sodium (Polpharma, Gdańsk, Poland) injection administered intraperitoneally at $40 \mathrm{mg} / \mathrm{kg}$ body weight. Blood samples of rats at the age of 8 weeks were obtained for hematological examination. Subsequently, necropsies of all rats were performed, and the collected organs (thymus and spleen) were weighed. One part of the spleen was aseptically obtained and rinsed with cold phosphate-buffered saline $(\mathrm{pH}$ 7.2) for further immunophenotyping, and then the second part of the spleen and the thymus were fixed in $4 \%$ buffered formalin solution for histological examination.

All investigators who performed their work in the laboratory (flow cytometry, cytokine assays, and histological evaluation) and analyzed the data statistically were blinded to which immunosuppressive regimen was used in the examined rats.

\section{Immunophenotyping - flow cytometry and cytokine assays}

The spleen was further sliced and pressed through nylon to Roswell Park Memorial Institute medium (RPMI)-1640. The liquid was transferred into a centrifuge tube containing the same volume of RPMI-1640 and centrifuged at 2,000 $\times g$ for 20 minutes at room temperature. The middle cloud layer was placed in lymphocyte isolation medium and centrifuged at $1,000 \times g$ for 10 minutes. The pellets were resuspended in RPMI-1640 medium. Cell viability was verified using trypan blue in Bürker's chamber. It was identified to be more than $90 \%$.

\section{Flow cytometry}

Cell suspensions prepared as mentioned earlier were stained for analysis with following monoclonal antibodies: A-RatCD3, anti-rat CD4PE, A-Rat CD8a, and anti-rat CD45RA. Flow cytometry was performed on LSR II Becton Dickinson flow cytometer (BD Biosciences, San Jose, CA, USA) and analyses were performed using FACSDiva version 6.2 (BD Biosciences).

\section{Cytokine assays}

Cell suspensions at the density of $2 \times 10^{6}$ were placed in wells $(0.5 \mathrm{~mL}$ of cells suspension in $1 \mathrm{~mL}$ of incubation medium). The incubation medium consisted of RPMI, $10 \%$ bovine serum, $50 \mu \mathrm{g}$ of gentamicin, and increasing amounts of concanavaline $\mathrm{A}$ (ConA $-0,2$, and $5 \mu \mathrm{g} / \mathrm{mL})$. We estimated the proliferative response to this mitogen as described previously. ${ }^{4}$ The isolated lymphocytes were incubated on well plates for 72 hours at $37^{\circ} \mathrm{C}$ under an atmosphere containing $5 \% \mathrm{CO}_{2}$. After incubation, suspensions were centrifuged at $1,000 \times g$ for 10 minutes. The concentrations of cytokines (interferon- $\gamma$ [IFN $\gamma]$, interleukine 4 [IL-4], IL-10, and IL-17) were measured by enzyme-linked immunoassays according to manufacturer's instructions (BD OptEIA Set Mouse IFN $\gamma$, IL-4, and IL-10 for IFN $\gamma$, IL-4, and IL-10, respectively [BD Biosciences]; Mouse IL-17A [homodimer] ELISA Ready-SET-GO for IL-17 [Affymetrix, Santa Clara, CA, USA]).

\section{Histological evaluation and its criteria}

Paraffin slides $(3 \mu \mathrm{m})$ of the spleen and the thymus were stained with hematoxylin-eosin, and a general histological examination was undertaken. The percentage area shares of cortex and medulla in relation to the entire area of lobule in thymus were measured. The samples were independently examined by two experienced pathologists.

\section{Drug concentration in blood}

Two separate groups of female rats $(n=14 \times 2)$ of corresponding age were used for the evaluation of drug concentrations in blood. These rats were given identical doses of the drugs by oral gavage (a full-dose and a half-dose group; every medication dose was adjusted based on body weight). The drug concentration was determined in accordance with literature ${ }^{9,16}$ after 4 hours of oral administration. The concentration of drugs in blood was determined after 1 week of taking the drugs once daily from the time of first administration to it being fully in the rats' bloodstream. The concentration of CsA was determined with Abbott AxSYM assay (Abbott Laboratories, Lake Bluff, IL, USA) (fluorescence polarization immunoassay - FPIA). To determine Tc level, we used IMx assay (microparticle enzyme immunoassay - MEIA), which was performed using an Abbott analyzer (Abbott Laboratories) at the Clinical Central Laboratory in Szczecin. The concentration of everolimus was determined at the Laboratory of Mass Spectometry IBB PAN in Warsaw using an original method of the author (ultra performance liquid chromatography/tandem mass spectrometry [UPLC/MS/MS]). ${ }^{17}$

\section{Statistical analysis}

The values of quantitative variables were analyzed with nonparametric tests (Kruskal-Wallis and Mann-Whitney $U$ test), because of most of the data were nonnormally distributed (as assessed by Shapiro-Wilk test). $P<0.05$ was set as the statistical significance level. Calculations were performed 
using Statistica 10 software (Dell Software, Round Rock, TX, USA).

\section{Results}

The concentrations of drugs in blood are shown in Table 1. The results of the research and statistical analysis are presented in Tables 2-4.

\section{Spleen and thymus weight}

There were no statistically significant differences in weight of the thymus and spleen in 19-day-old rats from the control and $\mathrm{CMG}$ groups (mean weight of thymus 0.10 versus $0.12 \mathrm{~g}$; mean weight of spleen 0.07 versus $0.1 \mathrm{~g}), 8$-week-old rats from the control and CMG groups (full dose of drugs; mean weight of thymus 0.46 versus $0.55 \mathrm{~g}$; mean weight of spleen 0.54 versus $0.50 \mathrm{~g}$ ), and 8-week-old rats from the control and half-dose treatment groups (control, CMG 0.5, TMG 0.5, and CEG 0.5 group, respectively: mean weight of thymus 0.46 versus 0.46 versus 0.52 versus $0.55 \mathrm{~g}$; mean weight of spleen 0.54 versus 0.55 versus 0.53 versus $0.63 \mathrm{~g}$ ).

\section{Hematology results}

Hematological parameters were only analyzed in 8-week-old rats. We found the following:

- Higher whole white blood cell count (arithmetic mean in the control group $6 \mathrm{G} / \mathrm{L}$; in the CMG group $8.53 \mathrm{G} / \mathrm{L}-$ $P=0.039$, Mann-Whitney $U$ test) as well as lymphocyte count (arithmetic mean in the control group $4.59 \mathrm{G} / \mathrm{L}$; in the CMG group $6.64 \mathrm{G} / \mathrm{L}-P=0.01$, Mann-Whitney $U$ test) in the CMG group (full-dose regimen)

- Decreased platelet count in the TMG group 0.5 (arithmetic mean in the control group $881.45 \mathrm{G} / \mathrm{L}$, in TMG group $0.5732 \mathrm{G} / \mathrm{L}-P=0.043$, Kruskal-Wallis test).

\section{Immunophenotyping results}

On assessing splenocytes by flow cytometry, the following results were obtained:

- Increased B lymphocyte, $\mathrm{CD} 3{ }^{+} \mathrm{CD} 8 \mathrm{~A}^{+}$lymphocyte, and natural killer $(\mathrm{NK})$ cell counts in the full-dose $\mathrm{CMG}$ group (Table 2)

- Increased B lymphocyte and $\mathrm{CD}^{+} \mathrm{CD} 8 \mathrm{~A}^{+}$lymphocyte counts in the TMG group 0.5

- Decreased T lymphocyte and NK cell counts in the CMG group 0.5

- Increased B lymphocyte and NK cell counts but decreased T lymphocyte counts in the CEG group 0.5 (Table 3 ).

\section{Cytokine assays}

In the control group and in all treatment groups, independently of dose, we found relatively low levels of IL-4, IL-10, and IFN $\gamma$ after administration of different doses of ConA $(0,2$, and $5 \mu \mathrm{g} / \mathrm{mL})$. The differences between them were not of statistical significance. We noticed increasing levels of IL-17 with increasing doses of ConA in all groups except for the CMG group (full dose), where this increase was blocked. This effect was dose-dependent - after a reduction

Table I The medication concentration in whole blood and weight of rats in study groups treated with full and half dose of immunosuppressive drugs (additional study groups)

\begin{tabular}{|c|c|c|c|c|}
\hline Drug and dose & $\begin{array}{l}\text { CMG group } \\
(n=3 \times 2)\end{array}$ & $\begin{array}{l}\text { TMG group } \\
(n=4 \times 2)\end{array}$ & $\begin{array}{l}\text { CEG group } \\
(n=4 \times 2)\end{array}$ & $\begin{array}{l}\text { Control group } \\
(n=3 \times 2)\end{array}$ \\
\hline Cyclosporin A (ng/mL) & $69.37 \pm 45.61$ & - & $50.35 \pm 8.80$ & - \\
\hline \multicolumn{5}{|l|}{ Dose $5 \mathrm{mg} / \mathrm{kg}$} \\
\hline Cyclosporin A (ng/mL) & $33.57 \pm 41.04$ & - & $33.53 \pm 12.84$ & - \\
\hline \multicolumn{5}{|l|}{ Dose 2.5 mg/kg } \\
\hline Tacrolimus (ng/mL) & - & $7 \pm 6.61$ & - & - \\
\hline \multicolumn{5}{|l|}{ Dose $4 \mathrm{mg} / \mathrm{kg}$} \\
\hline Tacrolimus (ng/mL) & - & $0.77 \pm 0.57$ & - & - \\
\hline \multicolumn{5}{|l|}{ Dose $2 \mathrm{mg} / \mathrm{kg}$} \\
\hline Everolimus (ng/mL) & - & - & $1.43 \pm 0.17$ & - \\
\hline \multicolumn{5}{|l|}{ Dose $0.5 \mathrm{mg} / \mathrm{kg}$} \\
\hline Everolimus (ng/mL) & - & - & $0.83 \pm 0.22$ & - \\
\hline \multicolumn{5}{|l|}{ Dose $0.25 \mathrm{mg} / \mathrm{kg}$} \\
\hline Body mass (g) & $240 \pm 21$ & $255 \pm 12.5$ & $245 \pm 22.5$ & $260 \pm 16$ \\
\hline \multicolumn{5}{|l|}{ Full-dose group } \\
\hline Body mass (g) & $250 \pm 50.1$ & $235 \pm 20$ & $225 \pm 11.5$ & $255 \pm 15$ \\
\hline Half-dose group & & & & \\
\hline
\end{tabular}

Notes: Results are presented as arithmetic mean \pm standard deviation. -, Not applicable.

Abbreviations: CMG, CsA + MMF + prednisone; TMG, Tc + MMF + prednisone; CEG, CsA + everolimus + prednisone; CsA, cyclosporine A; MMF, mycophenolate mofetil; Tc, tacrolimus. 
Table 2 Immunophenotyping (cytometry results) of 8-week-old rats from control and CMG group (full dose of drugs) - material from spleen

\begin{tabular}{|c|c|c|c|}
\hline Parameter/group & $\begin{array}{l}\text { Control group } \\
n=10\end{array}$ & $\begin{array}{l}\text { CMG group } \\
n=5\end{array}$ & $\begin{array}{l}\text { P-value (Mann- } \\
\text { Whitney } U \text { test) }\end{array}$ \\
\hline \multicolumn{4}{|c|}{$\mathrm{CD}^{-}{ }^{-} \mathrm{CD} 45^{+}$(B lymphocytes) \% } \\
\hline$A M \pm S D$ & $14.07 \pm 6.085$ & $|8.4| \pm 1.59$ & 0.019 \\
\hline Med & 12.825 & 18.35 & \\
\hline Range & $7.76-28.98$ & $16.58-20.73$ & \\
\hline \multicolumn{4}{|c|}{$\mathrm{CD}^{+}{ }^{+} \mathrm{CD}^{+}$(T lymphocytes) \% } \\
\hline$A M \pm S D$ & $34.06 \pm 8.34$ & $32.18 \pm 2.19$ & NS \\
\hline Med & 33.4 & 31.9 & \\
\hline Range & $21.8-53.2$ & $29.5-34.9$ & \\
\hline \multicolumn{4}{|l|}{$\mathrm{CD}^{+}{ }^{+} \mathrm{CD}_{8 \mathrm{~A}}{ }^{+} \%$} \\
\hline$A M \pm S D$ & $11.56 \pm 3.7$ & $16.5 \pm 2.16$ & 0.019 \\
\hline Med & 11.1 & 16.9 & \\
\hline Range & $6.1-19.7$ & $13.3-19.3$ & \\
\hline \multicolumn{4}{|c|}{$\mathrm{CD}^{-}{ }^{-} \mathrm{CD} \mathrm{A}^{+}$(NK cells) $\%$} \\
\hline$A M \pm S D$ & $3.52 \pm 1.69$ & $5.88 \pm 1.905$ & 0.028 \\
\hline Med & 2.85 & 5.9 & \\
\hline Range & $2.3-7.5$ & $3.5-8.8$ & \\
\hline
\end{tabular}

Abbreviations: AM, arithmetic mean; SD, standard deviation; Med, median; NS, nonsignificant difference; CMG, CsA + MMF + prednisone; NK, natural killer; CsA, cyclosporine A; MMF, mycophenolate mofetil.

in the dose of immunosuppressive drugs (CMG group 0.5), the levels of IL-17 began increasing again, as seen in other groups (Table 4).

\section{Histological evaluation}

Thymus

The images of thymus in 19-day-old rats from the control and $\mathrm{CMG}$ group were similar, and the amount of thymocytes in the cortex was comparable in both groups of rats. The percentage area share of cortex in the control group was on average $82.783 \%$ versus $75.816 \%$ in the CMG group $(P=0.019)$. The percentage area share of medulla in the control group was on average $16.915 \%$ versus $24.185 \%$ in the CMG group $(P=0.038)$. The percentage area share of cortex and medulla relative to the entire area of lobule was higher in favor of the medulla within the $\mathrm{CMG}$ group of rats.

The morphology of thymus of 8-week-old rats from the full-dose CMG group was similar to control rats, but in CMG

Table 3 Immunophenotyping (cytometry results) of 8-week-old rats in the treatment groups (half dose of drugs) - material from spleen

\begin{tabular}{|c|c|c|c|c|c|}
\hline Parameter/group & $\begin{array}{l}\text { Control group } \\
n=10\end{array}$ & $\begin{array}{l}\text { CMG group } 0.5 \\
n=10\end{array}$ & $\begin{array}{l}\text { TMG group } 0.5 \\
\mathrm{n}=10\end{array}$ & $\begin{array}{l}\text { CEG group } 0.5 \\
n=7\end{array}$ & $\begin{array}{l}P \text {-value (Kruskal- } \\
\text { Wallis test) }\end{array}$ \\
\hline \multicolumn{6}{|c|}{$\mathrm{CD}^{-}{ }^{-C D} 45^{+}$(B lymphocytes) \% } \\
\hline$A M \pm S D$ & $14.07 \pm 6.085$ & $|4.49 \pm 6.7|$ & $18.365 \pm 3.16$ & $|7.56 \pm 2.7|$ & 0.0665 \\
\hline Med & 12.825 & 13.005 & $18.58 *$ & $|8.2|^{*}$ & \\
\hline Range & $7.76-28.98$ & $5.4 I-27.29$ & $11.7-24.16$ & $|3.0-2| .5 \mid$ & \\
\hline \multicolumn{6}{|c|}{$\mathrm{CD}^{+}{ }^{+} \mathrm{CD} 4^{+}$(T lymphocytes) \% } \\
\hline$A M \pm S D$ & $34.06 \pm 8.34$ & $18.35 \pm 9.84$ & $36.42 \pm 3.16$ & $26.13 \pm 3.89$ & 0.0010 \\
\hline Med & 33.4 & $14.75 * *$ & 36.6 & $24.7^{*}$ & \\
\hline Range & $21.8-53.2$ & $4.6-34.0$ & $29.6-42.3$ & $21.6-33.6$ & \\
\hline \multicolumn{6}{|l|}{$\mathrm{CD}^{+}{ }^{+} \mathrm{CD} 8 \mathrm{~A}^{+} \%$} \\
\hline$A M \pm S D$ & $11.56 \pm 3.7$ & $15.54 \pm 8.28$ & $19.44 \pm 2.4$ & $11.07 \pm 2.18$ & 0.0060 \\
\hline Med & 11.1 & 16.35 & $19.3 * *$ & 12.2 & \\
\hline Range & $6.1-19.7$ & $2.8-26.5$ & $15.6-22.9$ & $7.3-13.0$ & \\
\hline \multicolumn{6}{|c|}{$\mathrm{CD}^{-}{ }^{-} \mathrm{CD}^{-} \mathrm{A}^{+}$(NK cells) $\%$} \\
\hline$A M \pm S D$ & $3.52 \pm 1.69$ & $11.57 \pm 3.94$ & $4.22 \pm 0.975$ & $9.7 I \pm 3.76$ & 0.0000 \\
\hline Med & 2.85 & $10.8^{* *}$ & 4.25 & $9.4 * *$ & \\
\hline Range & $2.3-7.5$ & $7.3-19.6$ & $2.8-6.0$ & $4.7-16.6$ & \\
\hline
\end{tabular}

Notes: $* P<0.05$ versus control group, $* * P<0.001$ versus control group, Mann-Whitney $U$ test.

Abbreviations: AM, arithmetic mean; SD, standard deviation; Med, median; CMG, CsA + MMF + prednisone; TMG, Tc + MMF + prednisone; CEG, CsA + everolimus + prednisone; CsA, cyclosporine A; MMF, mycophenolate mofetil; Tc, tacrolimus; NK, natural killer. 
Table 4 IL- 17 profile after incubation of lymphocytes from spleen with different doses of ConA (0, 2, and $5 \mu \mathrm{g} / \mathrm{mL})$

\begin{tabular}{lllllll}
\hline Parameter/group & $\begin{array}{l}\text { Control group } \\
\mathbf{n = 1 2}\end{array}$ & $\begin{array}{l}\text { CMG group } \\
\mathbf{n = 5}\end{array}$ & $\begin{array}{l}\text { CMG group } \mathbf{0 . 5} \\
\mathbf{n}=\mathbf{1 0}\end{array}$ & $\begin{array}{l}\text { TMG group 0.5 } \\
\mathbf{n = 1 0}\end{array}$ & $\begin{array}{l}\text { CEG group 0.5 } \\
\mathbf{n}=\mathbf{7}\end{array}$ & $\begin{array}{l}\text { P-value (Kruskal- } \\
\text { Wallis test) }\end{array}$ \\
\hline IL-I7 & & & & & & \\
ConA0 & 29.923 & 45.569 & 2.404 & 0 & 0 & $0.1416(\mathrm{NS})$ \\
ConA2 & 143.78 & $0^{*}$ & 87.876 & 135.775 & 66.951 & 0.0283 \\
ConA5 & 230.701 & $11.034^{* *}$ & 204.287 & 335.653 & 301.49 & 0.0185 \\
\hline
\end{tabular}

Notes: Results are presented as arithmetic mean for all groups (control group; full-dose CMG group, and all half-dose groups). $* P<0.01, * * P<0.06$ versus control group, Mann-Whitney $U$ test.

Abbreviations: ConA, concanavaline A; IL, interleukine; NS, difference nonsignificant; CMG, CsA + MMF + prednisone; TMG, Tc + MMF + prednisone; CEG, CsA + everolimus + prednisone; CsA, cyclosporine; MMF, mycophenolate mofetil; Tc, tacrolimus.

rats, there were much more erythrocytes in medulla, cortex, and the cortex-medulla boundary. The percentage area share of cortex in the control group was on average $80.138 \%$ versus $76.106 \%$ in the CMG group. The percentage area share of medulla in the control group was on average $19.861 \%$ versus $23.87 \%$ in the CMG group. Differences were not statistically significant.

Results after administration of half-dose regimens were as follows: the percentage area share of cortex in CMG group 0.5 was on average $72.695 \%$ versus $78.032 \%$ in TMG group 0.5 versus $80.114 \%$ in CEG group 0.5 (control group $80.138 \%$ ). The percentage area share of medulla in CMG group 0.5 was on average $27.308 \%$ versus $21.968 \%$ in TMG group 0.5 versus $18.817 \%$ in CEG group 0.5 (control group 19.861\%). Differences were not statistically significant in TMG group 0.5 and CEG group 0.5 in comparison to the control group.

In $\mathrm{CMG}$ group 0.5 , the percentage area share of cortex and medulla in relation to the entire area of lobule was higher in favor of the medulla (the percentage area share of cortex and medulla versus the control group - for both measurements $P=0.017)$. In all half-dose groups, medulla of the thymus penetrated the cortex, and more erythrocytes within medulla were observed, especially in rats from TMG group 0.5 ; in this group of rats, the cortex was also strongly infiltrated by red blood cells. The cortex in CMG group 0.5 and CEG group 0.5 contained many outbreaks of lighter stained cells. In addition, a disturbed structure of septal connective tissue seemed to be inserted into the thymus lobule in rats from CEG group 0.5 .

\section{Spleen}

The images of spleen from control 19-day-old rats and rats from the CMG group were similar, but in red pulp of rats from the CMG group, there were more distended sinusoidal capillaries filled by numerous erythrocytes; also, the number of megakaryocytes and multinucleated giant cells was higher than that in the control group. In the red pulp of rats from the CMG group, an increase in the amount of eosinophils and dark staining cells resembling lymphocytes was also observed.

The spleen morphology of 8-week-old rats from the fulldose CMG group was also similar to rats from the control group; however, the number of big cells (megakaryocytes) was lower, and the number of small cells with dark staining nucleus (lymphocytes) was higher than that in the control group.

The histological structure of spleen in half-dose regimen groups was typical: the white pulp contained lymphatic follicles limited by marginal zone, and each follicle had a central artery enveloped with periarterial lymphoid sheath; the red pulp was composed of splenic sinusoids and splenic cords with the area of extramedullary hematopoiesis. However, white pulp area reduction was observed in CMG group 0.5 and TMG group 0.5 in contrast to CEG group 0.5, where enlarged white pulp area with numerous lymphatic follicles with a germinal center was found in comparison to control rats. In addition, extramedullary hematopoiesis area was present in CMG group 0.5 and CEG group 0.5 . Rats from CEG group 0.5 had more developed and darker staining marginal zone in lymphoid follicle of white pulp compared to rats from other treatment groups. The splenic sinusoids were more expanded in rats from TMG group 0.5 and CEG group 0.5 than rats from CMG group 0.5; moreover, spleen of rats from CEG group 0.5 contained hemosiderin accumulation and had more eosinophils, mast cells, and macrophages and less megakaryocytes than rats from $\mathrm{CMG}$ group 0.5 .

\section{Discussion}

Immunotoxicity can be defined as an adverse effect on the immune system that occurs at a dose that produces no general systemic toxic effects. ${ }^{18}$ Exposure to immunosuppressive treatment during pregnancy can result in persistent impairment of the immune organs of both the mother and the fetus. ${ }^{1,19}$ The fetus is often more sensitive to many toxic 
agents. ${ }^{19,20}$ We found no statistically significant differences in the weight of thymus and spleen in all groups independently of the age and dose of immunosuppressive drugs. This corresponds to the observation of Barrow et al ${ }^{19}$ who showed that prenatal exposure to CsA also did not cause such alterations. Only postnatal treatment of juvenile rodents with CsA has been reported to result in morphological and functional abnormalities of the thymus and spleen..$^{19}$ Other authors have observed a dose-dependent reduction in thymus weight only in adult male rats treated with $\mathrm{CsA},{ }^{18}$ and $\mathrm{CsA}$ and $\mathrm{MMF},{ }^{21}$ while the spleen remained unaffected.

Analyzing the hematology results, we found higher white cell count and lymphocyte count only in rats from the CMG group (full dose of drugs); in half-dose regimens, we found a decreased number of platelets in rats from TMG group 0.5 , and these are our unique observations; other authors have obtained different results. In the study by Crevel et al, ${ }^{18}$ a trend toward a decrease in lymphocytes and an increase in neutrophils was observed. Also, a dose-dependent reduction in hematocrit and hemoglobin concentrations was found after exposure of rats to CsA; MMF alone or used in combination with CsA resulted in a reduction in white blood cell counts and lymphocyte counts, a decrease in red blood counts and hemoglobin concentration, and an increase in platelet counts. ${ }^{21}$ These studies, however, were carried out on male adult rats. In our study, anemia in juvenile rats was not observed.

The flow cytometry analysis of the spleen revealed that there were more B lymphocytes in rats exposed in utero to CMG regimen full dose and rats from TMG group 0.5 and CEG group 0.5. Rats from CMG group 0.5 and $\mathrm{CEG}$ group 0.5 had less $\mathrm{T}$ lymphocytes. The percentage of $\mathrm{CD}^{+} \mathrm{CD}^{2} \mathrm{~A}^{+}$ lymphocytes was elevated in the CMG full-dose group and TMG group 0.5. NK cells were increased in both $\mathrm{CMG}$ groups independently of dose and in the CEG group 0.5 . Data from previous studies also show increased NK cell activity with CsA treatment in rats. ${ }^{18}$ In female rats treated during pregnancy with $\mathrm{CsA}$, a reduction in graft-versus-host reactivity was observed using their splenocytes. ${ }^{22}$ In juvenile rats treated with CsA postnatally, the reduction in T-cell counts in the spleen was due to a decrease in the number of both helper $\mathrm{CD} 4^{+}$and cytotoxic $\mathrm{CD} 8^{+} \mathrm{T}$-cells. ${ }^{23,24}$ Addition of CsA to the fetal thymus culture resulted in a decreased yield and inhibition of thymocytes $\mathrm{CD} 4^{+} \mathrm{CD} 8^{-}, \mathrm{CD}^{-} \mathrm{CD}^{+}$, and a decrease in the number of $\mathrm{CD} 4^{+} \mathrm{CD} 8^{+}$thymocytes, whereas the development of $\mathrm{CD}^{-} \mathrm{CD}^{-}, \mathrm{CD}^{+}$, and $\mathrm{CD} 4^{-}$ CD8 ${ }^{-}$thymocytes was not affected. ${ }^{25}$ Increased number of
B lymphocytes in most treatment groups seems remarkable. The mechanistic model of a particular immunosuppressant activity is clearer with regard to T-cell biology. Besides, primary lymphoid organs where B-cells mature (bone marrow and liver) have not been investigated in this study. The network of genes and their products involved in B-cell proliferation and maturation is complex, and the hierarchy among these has not been fully recognized. ${ }^{26}$ However, lessons from clinical experience appear complementary to our observations concerning B-cells. Certain types of posttransplant lymphoproliferative disorders, clinically resembling non-Hodgkin lymphomas, result from Epstein-Barr virus (EBV) infection simultaneously with immunosuppression or immunosuppression itself. ${ }^{27}$ A reduction in the doses of immunosuppressive drugs is a first-line treatment in these cases. The increase in B-cell number in this study points to whether certain forms of posttransplant lymphoproliferative disorders result only from impaired immune control of B-cell proliferation or if B-cell induction and maturation could possibly be affected by immunosuppressive agents themselves. Transcriptomic studies will possibly be able to shed some light on this matter.

The cytokines IFN $\gamma$, IL-4, IL-10, and IL-17 were chosen as representatives for the investigation of infants' immune system under immunosuppression during pregnancy. IFN $\gamma$ released by activated $\mathrm{CD} 4^{+} \mathrm{T}$-cells is involved in promoting adaptive cellular immunity. ${ }^{28} \mathrm{IL}-4$ has been found to play a pivotal role in shaping the humoral immunity, promoting Th2 development, and stimulating B-cell proliferation. ${ }^{29,30}$ IL-10 belongs to the narrow group of regulatory cytokines. Released by Th2 lymphocytes, it attenuates adaptive cellular response. ${ }^{31}$ We found relatively low and comparable levels of IFN $\gamma$, IL-4, and IL-10 after the administration of different amounts of ConA in all groups of juvenile rats. The final cytokine chosen for this study, IL-17, was discovered nearly 10 years ago. The physiological role of IL-17 is connected to antibacterial and antifungal defense and has focused the interest of transplantologists with regard to acute and chronic allograft injury. ${ }^{32,33}$ We noticed increasing levels of IL-17 with increasing doses of ConA in all groups except the $\mathrm{CMG}$ full-dose group. This effect was dose-dependent - after a reduction of CsA and MMF doses, this blockade disappeared - and we noticed increasing levels of IL-17 again (two- to threefold increase from ConA $2 \mu \mathrm{g} / \mathrm{mL}$ to ConA $5 \mu \mathrm{g} / \mathrm{mL}$ ). The investigation of cytokines related to main immune response pathways aimed at providing closer insight into functional parameters of infant immunity, where, at the 
same time, calcineurin inhibitors (CsA and Tc) block the mechanisms of adaptive cellular response connected to IFN $\gamma$ mode of action. Simultaneously, IFN $\gamma$ suppresses IL-17dependent axis. ${ }^{34}$ Depression of IFN $\gamma$ by immunosuppressive agents has not been fully indicated in this study because of the poor IFN $\gamma$ secretion in the stimulated control group. However, this model was based on nonspecific stimulant (ConA) and could be possibly verified using more specific stimulants. ${ }^{35}$ Nevertheless, it is believed by the authors that this is the first in vitro study showing drug dose-dependent, nonspecific induction of IL-17 under immunosuppressive conditions in newborns. It seems reasonable to hypothesize that naive infants' lymphocytes are prone to activate IL-17dependent pathway in a nonspecific manner simultaneously to the mother's immunosuppression. Whether this is dependent on IFN $\gamma$ suppression still needs to be resolved.

Although there were no statistically significant differences in the weight of the thymus and spleen in all groups of rats, we found differences on histological evaluation of these organs. The percentage area share of cortex and medulla in relation to the entire area of lobule was higher in favor of the medulla within the CMG group of 19-day-old rats (full dose) and 8-week-old rats from CMG group 0.5. In all halfdose groups, the medulla of the thymus penetrated the cortex of the organ. In the study by Pally et al, ${ }^{21} \mathrm{CsA}$ was the only immunosuppressive drug that could produce a replacement of medulla by a cortex-like area, without affecting thymus weight. Tc in adult rats, similar to CsA, caused thymic medullary atrophy. ${ }^{36}$ However, when a combination of drugs was used, MMF together with CsA (or even alone) in adult rats gave a dose-dependent reduction in thymus weight accompanied by lymphodepletion in the cortex, ${ }^{22}$ which was consistent with our observation. CsA treatment in pregnant rats delayed thymus development in their offspring but did not cause persisting morphological alterations. ${ }^{37}$ Apart from the changes in the thymus, the newborn rats showed temporary defects in the development of spleen, liver, and bone marrow. ${ }^{1}$ The structure of the hemopoietic organs resembled those of the controls 30 days after birth. These results indicate that a delay in the development of the organs studied was due to the transplacental passage of CsA, and the injury is reversible and disappears with age. Moreover, in the histological evaluation of thymus, a disturbed structure of septal connective tissue was noticed in rats from CEG group 0.5. This is due to the presence of everolimus in this regimen mTOR inhibitors are well known for their antiproliferative and antifibrotic effects. . $^{14,38}$
On histological examination, the spleen of rats from CMG group 0.5 and TMG group 0.5 showed reduction of white pulp area in contrast to rats from CEG group 0.5 that had enlarged white pulp area. In addition, rats from $\mathrm{CMG}$ group 0.5 and CEG group 0.5 showed an increase of the area of extramedullary hematopoiesis. Rats from CEG group 0.5 had much more developed and darker staining marginal zone in the lymphoid follicle of white pulp than other rats from treatment groups. In a similar study in rats treated only with CsA, the authors observed atrophy of the white pulp of the spleen, while the red pulp showed histiocytosis; CsA in a dose higher than $5 \mathrm{mg} / \mathrm{kg}$ caused reduced extramedullary hematopoiesis. ${ }^{18}$

We have considered what potential implications for humans could be hypothetically obtained from this study. It is possible that we can expect changes in cell composition in human immune organs as well as differences in pattern of cytokines released by these cells. The doses of immunosuppressants in therapy during pregnancy should be reduced to the lowest possible levels (but still safe enough to maintain stable graft function) to reduce teratogenicity (more pups were delivered after a reduction in doses). Moreover, the production of some cytokines (like IL-17) could be less affected after a decrease in dosage of immunosuppressive drugs.

\section{Conclusion - impact of treatment on the progeny of rats}

1. Despite different proportions of spleen white pulp components as well as splenocyte subpopulations in particular groups, IL-17 production by splenocytes was efficiently induced under all the protocols except for full-dose CMG.

2. Drug regimen-dependent differences in cell composition of spleen sinusoids as well as extramedullary hematopoiesis were observed.

3. Disruption of thymus medulla/cortex proportions combined with cortex lymphodepletion was present in all treatment groups.

\section{Author contributions}

All authors contributed toward data analysis, drafting and revising the paper and agree to be accountable for all aspects of the work.

\section{Disclosure}

The authors report no conflicts of interest in this work. 


\section{References}

1. Rezzani R, Rodella L, Bianchi R. Cyclosporine and pregnancy in the rat. Transplantation. 1997;63(1):164-167.

2. Sgro MD, Barozzino T, Mirghani HM, et al. Pregnancy outcome post renal transplantation. Teratology. 2002;65(1):5-9.

3. Armenti VT, Radomski JS, Moritz MJ, Philips LZ, McGrory CH, Coscia LA. Report from the National Transplantation Pregnancy Registry (NTPR): outcomes of pregnancy after transplantation. Clin Transpl. 2000:123-134.

4. Atallah D, El Kassis N, Salameh C, et al. Pregnancy and renal transplantation. J Med Liban. 2015;63(3):131-137.

5. Melnikova VI, Afanasyeva MA, Voronova SN, et al. The effect of catecholamine deficit on the development of the immune system in rats. Dokl Biol Sci. 2012;443:68-70.

6. Yamatoya H, Kawaguchi H, Fukuda T, et al. Data on Wistar Hannover rats from an immunotoxicity study. Exp Anim. 2012;61(2): $171-175$.

7. Katz LA, Takizawa M, Joffe II, Stein B, Fallon MD, Epstein S. Comparison of the effects of FK 506 and cyclosporine on bone mineral metabolism in the rat. Transplantation. 1991;52(3):571-574.

8. Jolicoeur EM, Qi S, Xu D, Dumont L, Daloze P, Chen H. Combination therapy of mycophenolate mofetil and rapamycin in prevention of chronic renal allograft rejection in the rat. Transplantation. 2003;75(1): $54-59$.

9. Ma Y, Kobayashi T, Kuzuya T, et al. Is absorption profile of cyclosporine really important for effective immunosuppression? Biol Pharm Bull. 2006;29(2):336-342.

10. Westrhenen R, Aten J, Hajji N, et al. Cyclosporin A induces peritoneal fibrosis and angiogenesis during chronic peritoneal exposure to a glucose-based, lactate-buffered dialysis solution in the rat. Blood Purif. 2007;25(5-6):466-472.

11. Sagiroglu T, Sezer A, Torun N, et al. Protective effect of everolimus on renal ischemia reperfusion injury in rats. Saudi J Kidney Dis Transpl. 2014;25(2):294-302.

12. Viklický O, Müller V, Zou H, Szabó A, Vitko S, Heemann U. RAD reduces compensatory renal graft hypertrophy in a rat model of chronic rejection. Transplant Proc. 2001;33(3):2320-2321.

13. Martinez-Palli G, Hirose R, Liu T, et al. Donor pre-treatment with everolimus or cyclosporine does not reduce ischaemia-reperfusion injury in a rat kidney transplant model. Nephrol Dial Transplant. 2011; 26(6):1813-1820.

14. Kurdián M, Herrero-Fresneda I, Lloberas N, et al. Delayed mTOR inhibition with low dose of everolimus reduces TGF $\beta$ expression, attenuates proteinuria and renal damage in the renal mass reduction model. PLoS One. 2012;7(3):e32516.

15. Piao SG, Bae SK, Lim SW, et al. Drug interaction between cyclosporine and mTOR inhibitors in experimental model of chronic cyclosporine nephrotoxicity and pancreatic islet dysfunction. Transplantation. 2012; 93(4):383-389.

16. Schmitz V, Klawitter J, Bendrick-Peart J, et al. Metabolic profiles in urine reflect nephrotoxicity of sirolimus and cyclosporine following rat kidney transplantation. Nephron Exp Nephrol. 2009;111(4): e80-e91.

17. Tszyrsznic W, Borowiec A, Pawlowska E, et al. Two rapid ultra performance liquid chromatography/tandem mass spectrometry (UPLC/MS/MS) methods with common sample pretreatment for therapeutic drug monitoring of immunosuppressants compared to immunoassay. J Chromatogr B Analyt Technol Biomed Life Sci. 2013; 928:9-15.

18. Crevel RW, Buckley P, Robinson JA. The value of in vitro immune function tests in the detection of potential immunotoxicants. Toxicol In Vitro. 1994;8(5):1021-1025.
19. Barrow PC, Horand F, Ravel G. Developmental immunotoxicity investigations in the SD rat following pre- and post-natal exposure to cyclosporin. Birth Defects Res B Dev Reprod Toxicol. 2006;77(5): 430-437.

20. Schwenk M, Gundert-Remy U, Heinemeyer G, et al. Children as a sensitive subgroup and their role in regulatory toxicology: DGPT workshop report. Arch Toxicol. 2003;77(1):2-6.

21. Pally C, Tanner M, Rizvi H, et al. Tolerability profile of sodium mycophenolate (ERL080) and mycophenolate mofetil with and without cyclosporine (Neoral) in the rat. Toxicology. 2001;157(3): 207-215.

22. Cunningham C, Thomson AW, Power DA, Mason RJ, Catto GR. The effect of cyclosporine on humoral and cellular alloreactivity to allogeneic pregnancy in rats. Transplantation. 1986;42(4):400-403.

23. Allais L, Condevaux F, Fant P, Barrow PC. Juvenile toxicity of cyclosporin in the rat. Reprod Toxicol. 2009;28(2):230-238.

24. Holladay SD, Luster MI. Developmental immunotoxicology. In: Kimmel CA, Buelke-Sam J, editors. Developmental Toxicology, 2nd ed. New York, NY: Raven Press; 1994:93-118.

25. Kosugi A, Zuniga-Pflucker JC, Sharrow SO, Kruisbeek AM, Shearer GM. Effect of cyclosporin A on lymphopoiesis. II. Developmental defects of immature and mature thymocytes in fetal thymus organ cultures treated with cyclosporin A. J Immunol. 1989;143(10):3134-3140.

26. Boller S, Grosschedl R. The regulatory network of B-cell differentiation: a focused view of early B-cell factor 1 function. Immunol Rev. 2014; 261(1):102-115.

27. Singavi AK, Harrington AM, Fenske TS. Post-transplant lymphoproliferative disorders. Cancer Treat Res. 2015;165:305-327.

28. Ascough S, Ingram RJ, Chu KK, et al. $\mathrm{CD}^{+} \mathrm{T}$ cells targeting dominant and cryptic epitopes from Bacillus anthracis lethal factor. Front Microbiol. 2016;6:1506.

29. Chapoval S, Dasgupta P, Dorsey NJ, Leegan AD. Regulation of the T helper cell type 2 (Th2)/T regulatory cell (Treg) balance by IL-4 and STAT6. J Leukoc Biol. 2010;87(6):1011-1018.

30. Forbes E, van Panhuys N, Min B, Le Gros G. Differential requirements for IL-4/STAT6 signalling in CD4 T-cell fate determination and Th2immune effector responses. Immunol Cell Biol. 2010;88(3):240-243.

31. Kim HY, Kim HS. Dimethylarginine dimethylaminohydrolase-1 mediates inhibitory effect of interleukin-10 on angiotensin II-induced hypertensive effects in vascular smooth muscle cells of spontaneously hypertensive rats. Cytokine. 2016;77:203-210.

32. Pagliari C, Simões Quaresma JA, Kanashiro-Galo L, et al. Human kidney damage in fatal dengue hemorrhagic fever results of glomeruli injury mainly induced by IL17. J Clin Virol. 2016;75:16-20.

33. Sullivan JA, Adams AB, Burlingham WJ. The emerging role of TH17 cells in organ transplantation. Transplantation. 2014;97(5):48.

34. Harrington LE, Hatton RD, Mangan PR, et al. Interleukine 17-producing $\mathrm{T} \mathrm{CD} 4^{+}$lineage develop via a lineage distinct from type 1 and 2 lineages. Nat Immunol. 2005;6(11):1123-1132.

35. Zimmerman C, Weber A, Mausberg AK, Kieseier BC, Hartung HP, Hofstetter $\mathrm{HH}$. T cell activation status determines the cytokine pattern induced by zymosan and bacterial DNA both in thymocytes and splenocytes. Clin Exp Immunol. 2013;172(2):245-253.

36. Stephen M, Woo J, Hasan NU, Whiting PH, Thomson AW. Immunosuppressive activity, lymphocyte subset analysis, and acute toxicity of FK-506 in the rat. A comparative and combination study with cyclosporine. Transplantation. 1989;47(1):60-65.

37. Rezzani R, Rodella L, Corsetti G, Ventura RG. Effects of cyclosporin A on some accessory cells of rat thymus. Int J Exp Pathol. 1995;76(4): $247-254$.

38. Rowiński W, Wałaszewski J, Pączek L. Transplantologia kliniczna. Warsaw, Poland: PZWL; 2004. 


\section{Publish your work in this journal}

Drug Design, Development and Therapy is an international, peerreviewed open-access journal that spans the spectrum of drug design and development through to clinical applications. Clinical outcomes, patient safety, and programs for the development and effective, safe, and sustained use of medicines are a feature of the journal, which

has also been accepted for indexing on PubMed Central. The manuscript management system is completely online and includes a very quick and fair peer-review system, which is all easy to use. Visit http://www.dovepress.com/testimonials.php to read real quotes from published authors.

Submit your manuscript here: http://www.dovepress.com/drug-design-development-and-therapy-journal 